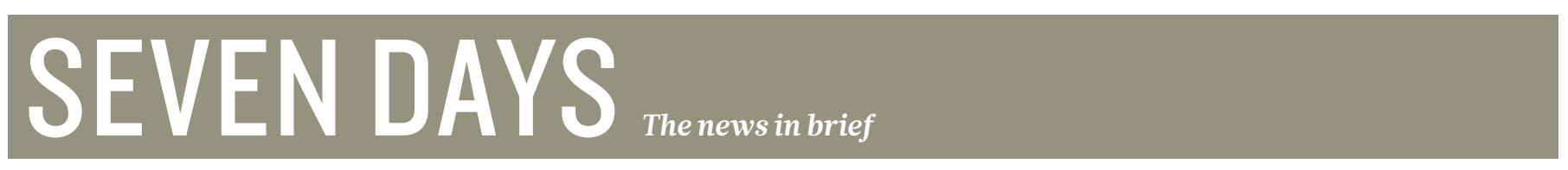

RESEARCH

\section{Gravitational waves}

Many of the world's best telescopes were turned to a little-known galaxy called NGC 4993 from 17 August, after an alert about a potential gravitational-wave detection in the region. Rumours abounded that the US-based Laser Interferometer Gravitational-wave Observatory (LIGO), possibly aided for the first time by the Virgo interferometer in Pisa, Italy, had picked up the signature of two neutron stars colliding in the galaxy. NASA's Fermi Gamma-ray Space Telescope detected a burst of $\gamma$-rays in roughly the same region of the sky as NGC 4993, which may indicate the aftermath of a neutron-star collision there, but which could instead come from an unrelated event. It would be a historic first for astronomy if telescopes saw signatures of the collision at the same time as interferometers 'heard' the event through vibrations in space-time. See go.nature. $\mathrm{com} / 2 \mathrm{w} 46 \mathrm{ja} 8$ for more.

\section{PEOPLE}

\section{Surprise Turing find}

Documents belonging to mathematician Alan Turing have been unearthed at the University of Manchester, $\mathrm{UK}$, and made available to researchers, the university announced on 25 August. The 148 items include a letter to Turing from British intelligence agency GCHQ and a draft BBC radio programme on artificial intelligence. Discovered in a storeroom filing cabinet in May, the collection does not include much personal correspondence. But it offers a glimpse of the code-breaker's working life between 1949 and his death in $1954-\mathrm{a}$ period for which archive

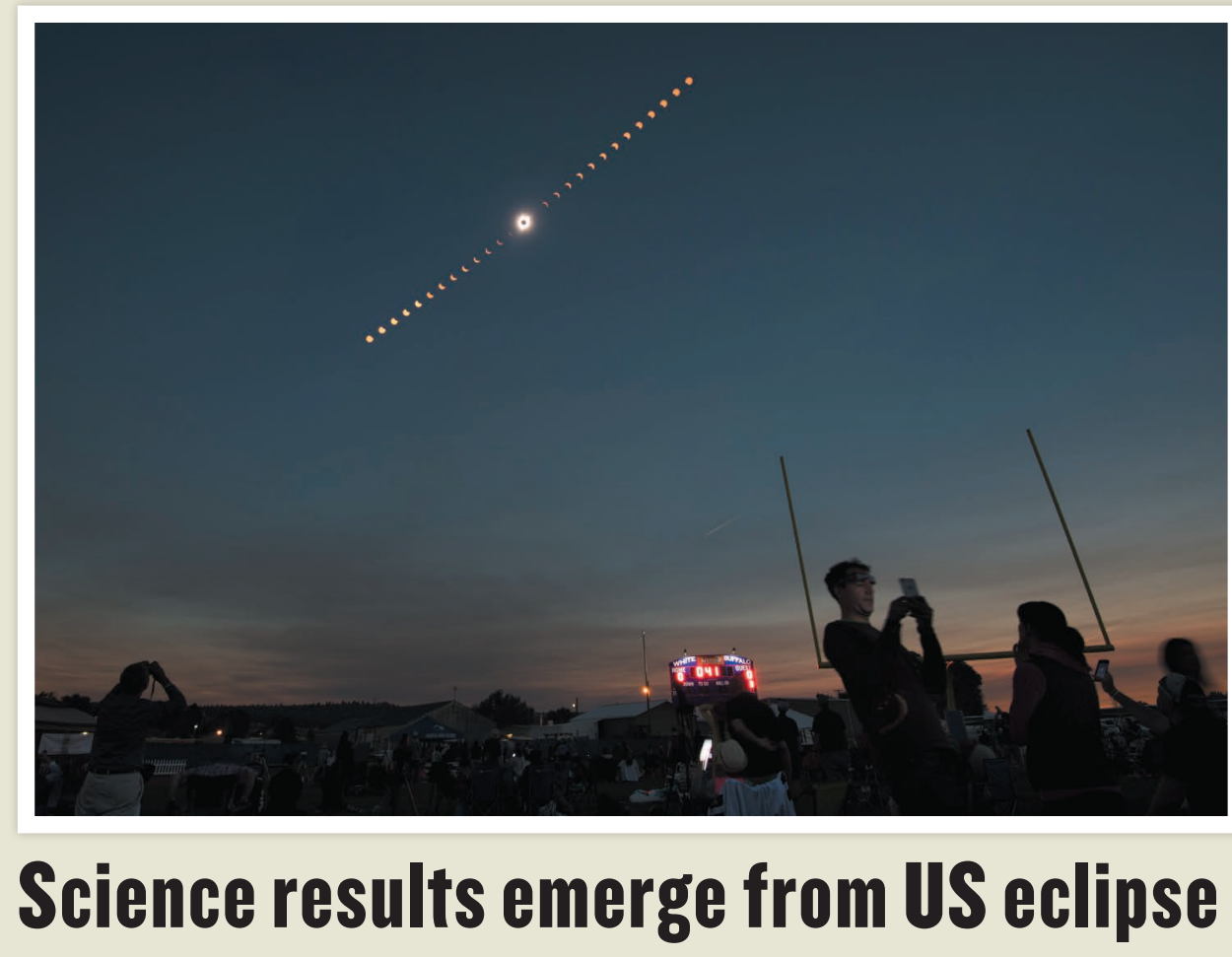

A total solar eclipse swept across the continental United States on 21 August, delighting skygazers and scientists. The path of totality crossed more than a dozen states, making it one of the most observed eclipses ever (composite image shown). A citizen-science project collected data from more than 55 telescopes to produce a high-resolution movie of the solar corona - the part of the Sun's atmosphere seen during totality. Among the professional scientific studies, a pair of NASA jets that chased the eclipse gathered high-resolution video of the corona, while ground-based expeditions collected information about ionized elements in the solar atmosphere. material is scarce, according to the university library's archivist. Some documents also give insight into his rather forthright personal opinions; his response to an invitation to a US conference in April 1953 was simply: "I would not like the journey, and I detest America."

\section{Science envoy quits}

An energy researcher at the University of California, Berkeley, resigned from his post as a science envoy for the US Department of State on 21 August, citing US President Donald Trump's "attacks on the core values of the United States". In a resignation letter addressed to Trump, Daniel
Kammen criticized the president's equivocal response to violent demonstrations by white supremacists in Charlottesville, Virginia, on 12 August. Kammen also condemned the Trump administration's "destructive" policies on energy and the environment, which he said have affected his work as a science envoy. See page 509 for more.

\section{FACILITIES}

\section{Big NASA missions}

NASA should continue its tradition of building spacecraft for large strategic spacescience missions such as the Hubble Space Telescope and the Mars Curiosity rover, says a 24 August panel report from the US National Academies of Sciences, Engineering, and Medicine. Like other agencies, NASA is struggling with a limited budget, and the panel examined whether big missions should remain a part of its portfolio. But the scientific return is worth it, the report found, as long as missions are managed well. Developing a range of cost options for large projects could help the agency to avoid problems such as those plaguing the James Webb Space Telescope, which has run billions of dollars over budget and is currently set to launch in 2018. 
PUBLISHING

\section{Preprint sites}

Six new preprint sites were

rolled out on 29 August.

The services, which host research papers before formal publication, include paleorXiv for palaeontology and INA-rXiv, a preprint server for Indonesian research. The other sites cover research on nutrition, library sciences, sports and exercise, and mind and contemplative practices. The servers are supported by software developed by the Center for Open Science in Charlottesville, Virginia, which already hosts eight other preprint services.

\section{ENVIRONMENT}

\section{Mind the penguins}

Chile has blocked plans for an iron mine that would have posed a threat to thousands of penguins. On 21 August, a Chilean government committee announced that Andes Iron, the local firm in charge of the US\$2.5-billion project, failed to put into place effective environmental protections to compensate for how mining activities might disturb wildlife. The project aimed to extract millions of tonnes of iron from a site in the northern Coquimbo region of Chile. But the site lies near the 888-hectare National Humboldt Penguin

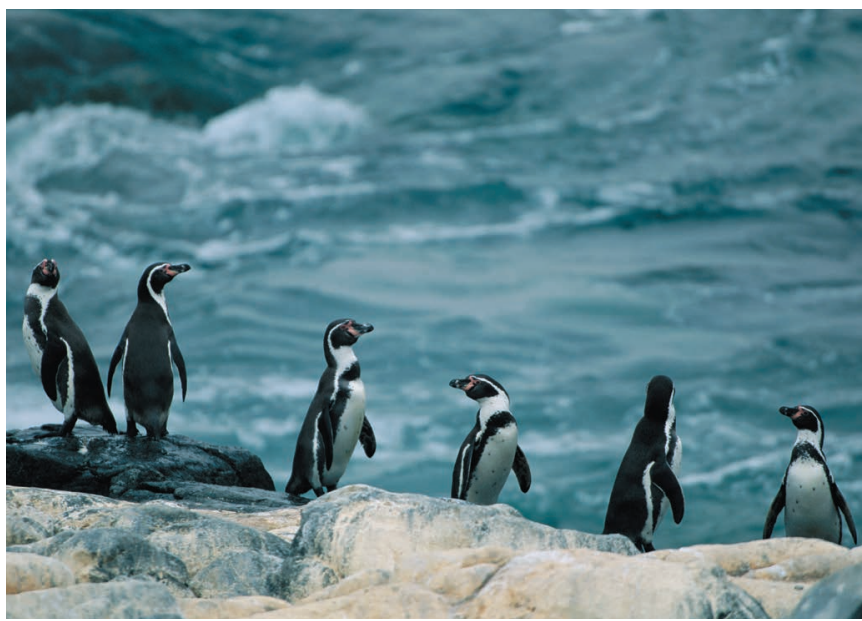

Reserve - a set of islands that are home to one of the world's largest breeding populations of Humboldt penguins (Spheniscus humboldti; pictured). The species is listed as 'vulnerable' by the IUCN Red List. Andes Iron says that it will appeal against the decision.

\section{Runaway salmon}

Thousands of Atlantic salmon have made a break for the Pacific Ocean after fish-farm nets in Washington state's San Juan Islands succumbed to "exceptionally high tides" on 19 August, according to the aquaculture company that owned the fish. The Washington Department of Fish \& Wildlife estimates that about 4,000-5,000 fish escaped from the pens, which contain more than 1.3 million kilograms of farmed fish. The incident has raised concern that the Atlantic species could threaten wild fish populations native to the region. Officials are temporarily suspending fishing regulations and encouraging recreational and commercial fishers to capture and sell any Atlantic salmon that they find.

\section{Australia land laws}

Contentious laws that allow landowners in New South Wales, Australia, to clear native vegetation on their properties came into effect on 25 August. Landowners in the country's most populous state can now remove more of certain types of vegetation, a loosening of the state's previous regulations. The decision has angered scientists and conservationists, who say that the laws put biodiversity

\section{TREND WATCH}

Illegal gold-mining in the Peruvian Amazon is on the rise again, according to a study published on 22 August (G. Asner and R. Tupayachi Environ. Res. Lett. 12, 094004; 2017). Miningrelated deforestation abated after a government crackdown in 2012, the authors found in their analysis of land-cover images. But since then, the mined area has increased by more than $40 \%$ in the Madre de Dios region, to 68,228 hectares. The region has some of the world's highest levels of animal diversity.

\section{GOLD-MINING IN THE AMAZON}

Deforestation from gold-mining continues apace in the

Peruvian Amazon, satellite data show - despite a

government crackdown in 2012.

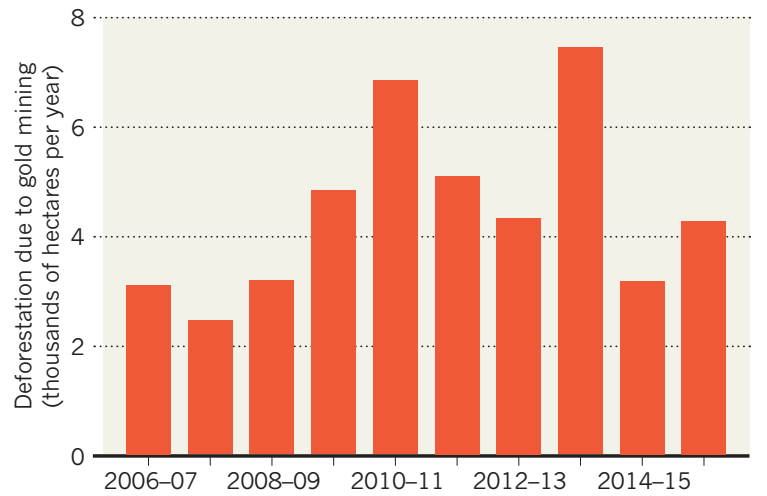

and threatened species at risk. But some farmers aren't satisfied either, saying that the amended rules are still too restrictive.

\section{BUSINESS}

\section{Quantum quest}

Australia’s first quantumcomputing hardware company started up on 23 August. Silicon Quantum Computing is a partnership between government, industry and the University of New South Wales in Sydney. It aims to develop and commercialize a prototype of a 10-quantumbit circuit made from silicon within five years - a stepping stone towards the creation of a silicon-based quantum computer. The company enters an increasingly crowded marketplace in quantum computing, with competition from technology giants such as Google and Microsoft.

\section{Drug costs cut}

Millions of people with hepatitis $\mathrm{C}$ may soon be able to afford the life-saving antiviral drug sofosbuvir. On 23 August, Gilead Sciences of Foster City, California, which sells the daily pills, said that it would license manufacturers of generic drugs to supply its antivirals in four middle-income countries Malaysia, Thailand, Belarus and Ukraine. That should slash prices: a 3-month course of the pills ranges from US $\$ 84,000$ in the United States to $\$ 12,000$ in Malaysia, but costs as little as $\$ 300$ in the 101 developing countries where generic versions are already permitted. Pressure had been mounting for the change: the Malaysian government has been considering a licence that would allow generics to be made or used in government facilities, overriding Gilead's patent, and Ukraine has already revoked a key patent on sofosbuvir that shortened Gilead's monopoly.

\section{$\rightarrow$ NATURE.COM}

For daily news updates see:

www.nature.com/news 